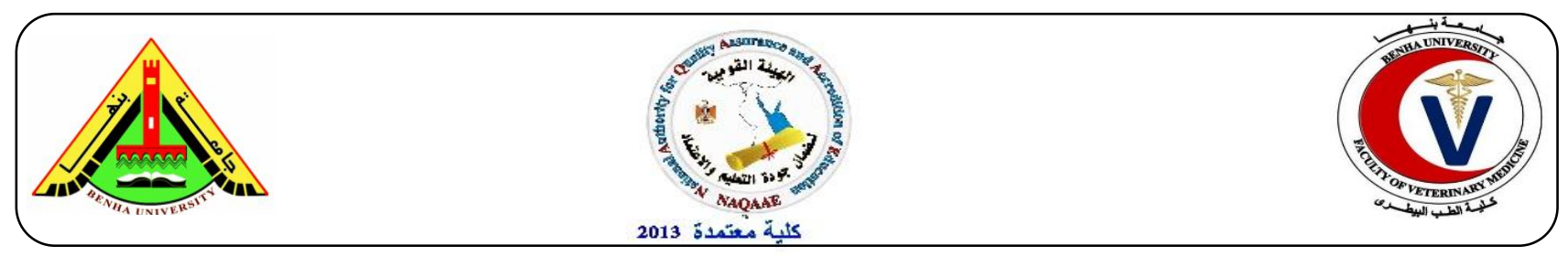

\title{
Vibrio Species in Fish and Shell Fish
}

\author{
Hemmat M. Ibrahim ${ }^{1}$, Reham A. Amin ${ }^{1}$, Nesreen Z. Eleiwa ${ }^{2}$ and Hanan R.M. Ghanaym ${ }^{2}$ \\ ${ }^{1}$ Food Hygiene Department, Faculty of Veterinary Medicine, Benha University, \\ ${ }^{2}$ Food Control Department, Animal Health Research Institute, Tanta Branch.
}

\section{A B S T R A C T}

A grand total of 100 random samples of fresh water fish with average weight $100-250 \mathrm{~g}$ (Oreochromis niloticus), marine water fish (Mugil cephalus), and shell fish (shrimp and crab) with average weight 10-50g were collected from different markets in Gharbia governorate for detection of Vibrio spp. The obtained results revealed that the incidence of Vibrio spp. in fresh water fish (Oreochromis niloticus) were 8 (32\%), with frequency of 2 (8\%), $2(8 \%), 2(8 \%), 1(4 \%)$ and $1(4 \%)$ for $V$. parahaemolyticus, $V$. mimicus, $V$. vulnificus, $V$. alginolyticus and $V$. fluvialis, respectively. In marine fish (Mugil cephalus),Vibrio spp. were 10 (40\%), the overall incidence in the samples was for $V$. parahaemolyticus 3(12\%), V. mimicus 2(8\%), V. alginolyticus $2(8 \%), \quad V$. vulnificus $1(4 \%)$ and $V$. fluvialis 2 (8\%). In shell fish (shrimp), Vibrio spp. were $13(52 \%)$ while the overall incidence in the samples was $V$. parahaemolyticus 4 (16\%), mimicus $3(12 \%)$, V. alginolyticus $2(8 \%), V$. vulnificus 1 (4\%), V. fluvialis $2(8 \%)$ and V. cholera 1 (4\%). Regarding crab, Vibrio spp. were 11 (44\%) while the overall incidence in the samples was $V$. parahaemolyticus $3(12 \%)$, mimicus 2 (8\%), V. alginolyticus 2 (8\%), V. vulnificus 1 (4\%), V. fluvialis $2(8 \%)$ and V. cholera 1 (4\%).

Keywords: Vibrio spp., fresh water fish, marine fish, shellfish, V. paraheamolyticus

\section{INTRODUCTION}

Fish is a nutrient-rich part of a healthful diet and its consumption is associated with potential health benefits, including neurological development during gestation and infancy (Hibbeln et al., 2007) and reduce risk of heart disease (Mozaffarian and Rimm, 2006).
The degeneration of fish is accelerated by microorganism associated with aquatic environment as well as contamination during post -harvest handling. When fish dies, microorganisms on the surface as well as gut and gills begin to utilize the fish protein and food nutrient resulting in loss of nutritional 
value as well as creating undesirable changes like off-flavors, texture and appearance (Jhonstone et al.,1994).

Seafood may be a vehicle for most of known bacterial pathogens as Vibrio spp. (Huss, 1997). Various outbreaks of bacterial disease associated with the consumption of seafood have been reported (Friesema et al., 2012). From these seafood-borne bacteria, Vibrio spp. which are Gram-negative rodshaped, oxidase positive, non-spore forming bacteria and halophilic bacteria that generally widespread in the coastal and estuarine environments (Austin, 2010).

The members of the genus Vibrio are considered as one of the main causes of gastroenteritis in humans. The majority of infections are attributed to consumption of raw or insufficiently cooked seafood products. The number of Vibrio spp. classified as pathogenic strains is at least 11strains (Holmberg et al., 1992), including $V$. cholerae as the main cause of diarrhea; $V$. parahaemolyticus as the cause of foodborne gastroenteritis (Ozer et al., 2008) and $V$. vulnificus which is known to cause 95\% of all deaths associated with seafood consumption (Rosche et al., 2006). Other pathogenic species includes $V$. alginolyticus; $V$. damsela; V. fluvialis; $V$. furnissii; $V$. hollisae; V. metschnikovii; V. cincinnatiensis and V. mimicus (Pruzzo et al., 2005).

The typical clinical symptoms of $V$. parahaemolyticus poisoning are acute dysentery and abdominal pain, accompanied with diarrhea, nausea, vomiting, fever, chills and water like stools (Shimohata and Takahashi, 2010). The faces of patients are mixed with mucus or blood and their blood pressure decreases dreamily leading to shock (Broberg et al., 2011). V. parahaemolyticus is very sensitive to heat (killed at $47^{\circ}-60^{\circ} \mathrm{C}$ ) and to ionizing radiation, as well as to halogens
(Adams and Moss, 2008). Most of vibrios secret enterotoxins in food, water or in the gastrointestinal tract (Nishibuchi and Depaola,2005).

Numerous studies have been conducted to determine the relationship between Vibrio spp. abundance and environmental factors such as temperature, salinity, nutrients and dissolved oxygen. As a result, these water quality characteristics can be used in a predictive manner to determine when these pathogens may be present (Gayatri, 2011).

The present work was planned out to determine the level of contamination of some fish (Mugil cephalus \& Oreochromis niloticus) and shell fish (shrimp \& crab) with vibrio species.

\section{MATERIAL AND METHODS}

A grand total of 100 random samples of fresh water (Oreochromis niloticus), marine water fish (Mugil cephalus), and shell fish (Shrimp and crab) were collected from different markets in Gharbia governorate. All samples were collected and transferred with a minimum of delay to the laboratory in ice box. All samples were subjected to the bacteriological examination.

\subsection{Preparation of samples:}

The scales and fins of the fish samples were removed, the skin was sterilized by alcohol and flamed by sterile spatula. The muscles above the lateral line were removed, while in shell fish (shrimp and crab) were washed with water then sterilized by alcohol and flamed and then the carapace was removed aseptically to expose the flesh. Ten grams were taken under aseptic conditions to sterile homogenizer containing $90 \mathrm{ml}$ of sterile alkaline peptone water (3\% $\mathrm{Nacl}$ and $\mathrm{pH} 8)$. 
2.2 Screening of Vibrio $s p$ It was done according to FDA (2004)

Isolation: Loopfuls from each previous cultured tube were separately streaked onto Thiosulfate citrate bile and sucrose agar (TCBS), then the medium was incubated at $37^{0}$ $\mathrm{C}$ for 24hrs. Typical colonies of $V$. mimicus, $V$. parahaemolyticus and $V$. vulnificus were appeared as smooth and green (sucrose negative), while colonies of $V$. cholerae, $V$. furnissii, $V$. alginolyticus and $V$. fluvialis were appeared as smooth and yellow (sucrose positive).

Presumptive identification: This was done according to the protocol recommended by ISO/ TS 21872-1 (2007) and ISO/ TS 21872-2 (2007).

\subsection{Confirmation of the results by multiplex} PCR:

It was done according to Tarr et al., (2007) and Rao and Surendran (2013).

The biochemically identified isolates and food samples were further verified genetically by PCR for detection of $16 \mathrm{~S}$ rRNA for all Vibrio spp, flaE for V.parahaemlyticus, hsp for V.vulnificus, sodB for V.mimicus and sodB for $V$.cholera.

\section{RESULTS}

Table (1): Incidence of vibrio spp. isolated from the examined samples of fish and shell fish ( $\mathrm{n}=25 \mathrm{of}$ each)

\begin{tabular}{ccc}
\hline Fish types & \multicolumn{2}{c}{ Vibrio spp. } \\
& No. & $\%$ \\
\hline Oreochromis niloticus & 8 & 32 \\
Mugil cephalus & 10 & 40 \\
Shrimn & 13 & 52 \\
Crab & 11 & 44 \\
Total & 42 & 42
\end{tabular}


Table (2): Incidence of vibrio spp. isolated from Oreochromis niloticus.

\begin{tabular}{ccc}
\hline Isolates & Number & $\%$ \\
\hline V. vulnificus & 2 & 8 \\
V. mimicus & 2 & 8 \\
V. fluvialis & 1 & 4 \\
V. cholerae & 0 & 0 \\
V. parahaemolyticus & 2 & 8 \\
V. alginolyticus & 1 & 4 \\
\hline
\end{tabular}

Table (3): Incidence of vibrio spp. isolated from Mugil cephalus.

\begin{tabular}{ccc}
\hline Isolates & Number & $\%$ \\
\hline V. vulnificus & 1 & 4 \\
V. mimicus & 2 & 8 \\
V. fluvialis & 2 & 8 \\
V. cholerae & 0 & 0 \\
V. parahaemolyticus & 3 & 12 \\
V. alginolyticus & 2 & 8 \\
\hline
\end{tabular}

Table (4): Incidence of vibrio spp. isolated from Shrimp.

\begin{tabular}{ccc}
\hline Isolates & Number & $\%$ \\
\hline V. vulnificus & 1 & 4 \\
V. mimicus & 3 & 12 \\
V. fluvialis & 2 & 8 \\
V. cholerae & 1 & 4 \\
V. parahaemolyticus & 4 & 16 \\
V. alginolvticus & 2 & 8 \\
\hline
\end{tabular}

Table (5): Incidence of vibrio spp. isolated from Crab

\begin{tabular}{ccc}
\hline Isolates & Number & $\%$ \\
\hline V. vulnificus & 1 & 4 \\
V. mimicus & 2 & 8 \\
V. fluvialis & 2 & 8 \\
V. cholerae & 1 & 4 \\
V. parahaemolyticus & 3 & 12 \\
V. alginolyticus & 2 & 8
\end{tabular}




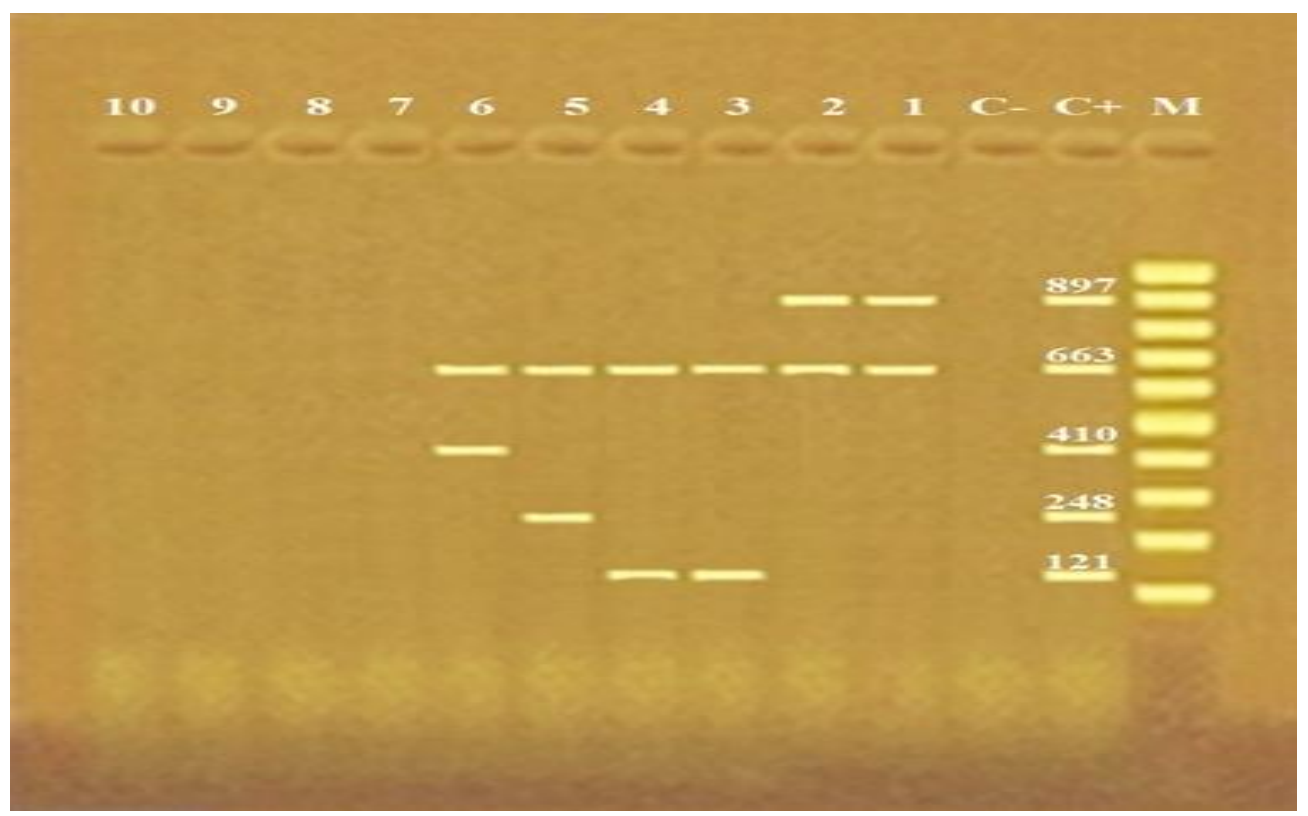

Fig (1): Agarose gel electrophoresis of multiplex PCR for characterization of $\operatorname{Vm} . \operatorname{sodB}(121 \mathrm{bp}$ ) for V.mimicus, Vc.sodB (248 bp) for V.cholera, Vv.hsp (410 bp) for V.vulnificus, 16S rRNA (663bp) for all Vibrio Spp. and Vp.flaE (897 bp) for V.parahaemolyticus.

Lane M: 100 bp ladder as molecular size DNA marker.

Lane C+: Control positive for Vm.sodB, Vc.sodB, Vv.hsp, 16S rRNA and Vp.flaE genes.

Lane 2: Control negative.

Lanes 1 \& 2: Positive V.parahaemolyticus for $16 S$ rRNA and Vp.flaE genes.

Lanes 3 \& 4: Positive V.mimicus for $16 S$ rRNA and Vm.sodB genes.

Lane 5: Positive V.cholera for $16 S$ rRNA and Vc.sodB genes.

Lane 6: Positive V.vulnificus for 16S rRNA and Vv.hsp genes.

Lanes 7, 8, 9 \&10: Negative samples for Vibrio species.

\section{Discussion}

Vibrio spp. inhabit marine environments and are associated with aquatic animals including fish, shellfish, shrimp, oyster, squid, prawn, and other freshwater animals (Sujeewa et al., 2009).

Incidence of Vibrio spp. isolated from the examined samples of fish recorded in Table (1) were $32 \%, 40 \%, 52 \%$ and $44 \%$ for freshwater (Oreochromis niloticus), marine

water fish (Mugil cephalus), and shell fish (Shrimp and crab), respectively. It is evident from the results recorded in table (1) that the high level of Vibrio spp. was in shrimp and crab when compared with samples from (Oreochromis niloticus) and (Mugil cephalus), this explained by Colakoglu et al. (2006) who found that shellfish make an excellent substrate for the microorganisms to live in the 
aquatic habitats due to lose texture of their flesh. When the aquatic system was contaminated with pathogenic vibrio, these bacteria become part of shellfish microflora.

Table (2) revealed that incidence in the Oreochromis niloticus samples were 1(4\%) for $V$. fluvialis and $V$. alginolyticus and were 2(8\%) for $V$. vulnificus, $V$. parahaemolyticus and $V$. mimicus while $V$. cholerae failed to be detected biochemically. These results lower than those reported by Noorlis et al., (2011) who found that Vibrio spp. could be detected at a prevalence of $98.67 \%$, whereas $V$. parahaemolyticus was detected at a prevalence of $24 \%$ from examined fresh water fish. The presence of Vibrio spp. in samples of freshwater fish suggests that foodborne illness could arise if these fish are consumed in the uncooked or found that Vibrio undercooked state. They could also cross- contaminate ready-to-eat foods that are in the same environment.

Table (3) declared that incidence in the samples Mugil cephalus were 2 (8\%) for each of $V$. alginolyticus, $V$. fluvialis and $V$. mimicus, and was 1 (4\%) for V. vulnificus. For $V$. parahaemolyticus was $3(12 \%)$ while, $V$. cholerae failed to be detected biochemically. On the other hand, Sanjeev (2002) recorded that the incidence of $V$. parahaemolyticus in fresh, marine and brackish water fish varied from 35 to $55 \%$. Also, higher results were reported by Jaksic et al. (2002) who isolated $V$. alginolyticus, $V$. fluvialis and $V$. mimicus from $14 \%, 9 \%$ and $28 \%$ of the examined samples of marine fish, respectively. Lower results were recorded by Raissy et al., (2013) who revealed that $29.3 \%$ of the examined fish were Vibrio positive. This high incidence probably reflects the nature of Vibrio spp. which is known as a halophilic waterborne bacterium that commonly inhabits environmental water sources worldwide.
Table (4) revealed that the of Vibrio.spp. incidence in shrimp samples was $4(16 \%)$ for $V$. parahaemolyticus and were $2(8 \%)$ for $V$. fluvialis and $V$. alginolyticus; 3 (12\%) for $V$. mimicus and 1(4\%) for $V$. cholerae and $V$. vulnificus. These results nearly similar to those of Amin et al. (2011) who isolated Vibrio spp. with a percentage of $57.3 \%$ from shrimps. These results are higher than results reported by Bakr-Wafaa et al., (2011) who detect Vibrio spp. in $32 \%$ of the total examined shrimp. This high result may indicate bad management practices (inadequate nutrition, overcrowding and overfeeding) in fish farms which can cause stress to the fish being cultured and thus make them more susceptible to microbial infection. Aquaculture in Egypt remains a growing, vibrant and important production sector for high-protein animal food that is easily digestible and of high biological value. However, a major setback in aquaculture is the outbreak of diseases, especially those caused by Vibrio spp. which considered significant economic and public health problems.

The incidence of Vibrio spp. in table (5) revealed that the incidence of Vibrio spp.in crab samples was $3(12 \%)$ for $V$. parahaemolyticus; 2(8\%) for each of $V$. fluvialis; $V$. alginolyticus and $V$. mimicus. While were 1 (4\%) for each of $V$. cholerae and $V$. vulnificus.

These results are higher than those reported by Utsalo (2008) who detect Vibrio spp.in $27.0 \%$ of the examined crabs.

The occurrence of Vibrio spp. in raw shellfish was common, especially shellfish from regions with temperate climates around the world from both natural and farm environments and all seafood types (Ducan and $\mathrm{Su}, 2005)$. 
Fish were conditioned by their environment if the growing and harvesting environment of fish was polluted chemically or microbiologically, the fish were also polluted. During transportation of these types of fish to landing center and wholesale market, these fish may also infect associate people during handling and when the consumers purchase those fishes, the associated microorganisms could be transferred to them (Begum et al.,2010).

The positive samples and its biochemically positive isolates also negative samples were subjected to $16 \mathrm{~S}$ rRNA and multiplex PCR as shown in Fig (1). This fig. illustrated that positive samples or isolates give two bands, one at $663 \mathrm{bp}$ and the $2^{\text {nd }}$ at its specific amplicon. Vm. $\operatorname{sodB}(121 \mathrm{bp})$ for V.mimicus, Vc.sodB (248 bp) for V.cholera, Vv.hsp (410 bp) for V.vulnificus, $16 S$ rRNA (663bp) for all Vibrio Spp. and Vp.flaE (897 bp) for V.parahaemolyticus while negatives not showed any band. Similar results showed by Tarr et al., (2007) and Rao and Surendran (2013).

\section{REFERENCES}

Adams, M.R. and Moss, M.O. (2008): Bacterial agents of food borne illness in: Food Microbiology (3rd Ed.) RSC, Surrey UK, pp. 182-269.

Amin, M.A.M.; Rizk, E.W. and Mohamed, T.S. (2011): Occurrence of some zoonotic vibrios in shellfish and diarrheic patients with regard to $t d h$ Gene in Vibrio Parahaemolyticus. Journal of American Science. 7(9): 449459.

Austin, B. (2010): Vibrios as causal agents of zoonoses. Vet Microbiol 140: 310-317.

Bakr-Wafaa, M. K.; Hazzah-Walaa,A.and
Abaza-Amani, F. (2011):Detection of Salmonella and Vibrio species in some seafood in Alexandria. J. American Sci., 7(9): 663-668.

Begum, M.; Abu Ahmed, A.; Das, M. and Parveen, S. (2010): Acomparative microbiological assessment of five types of selected fishes collected from two different markets. Advances in Biological Research. 4 (5): 259-265.

Broberg, C. A.; Calder, T. J. and Orth, K. (2011): Vibrio parahaemolyticus cell biology and pathogenicity determinants. Microbes Infect., 13:992-1001.

Colakoglu, F. A.; Sarmasik, A. and Koseglu, B. (2006): Occurrence of Vibrio spp. and Aeromonas spp. in shellfish harvested off Dardanelles cost of Turkey. Food Control. 17: 648-652.

Ducan, J. and Su, Y.C. (2005): Occurrence of Vibrio parahaemolyticus in two Oregon oyster-366 growing. Journal of Food Science. 70: 58-63.

Food and Drug Administration (FDA) (2004): Bacteriological Analytical Manual, Vibrio Chapter-9 (BAM).

Friesema, I.H.; De Jong, A.E.; Fitz James, I.A.; Heck, M.E.; van den Kerkhof, J.H. and Notermans, D.W. (2012): Outbreak of Salmonella thompson in the Netherlands since July 2012. Euro Surveill 17: 1-4, 142e150.

Gayathri, V. (2011): The prevalence and public health significance of human pathogenic Vibrio species in Hawai'i's diverse tropical coastal water environments. Water Resources Research Centre, University of Hawaii, http://www.wrrc.hawaii.edu.

Hibbeln, J. R.; Davis, J. M.; Steer, C.; Emmett, P.; Rogers, I.; Williams, C. and 
Golding, J. 2007. Maternal seafood consumption in pregnancy and neurodevelopmental outcomes in childhood (ALSPAC study): an observational cohort study. Lancet 369:578-585.

Holmberg, S.D. (1992). Vibrio. In: S. L. Gorbach, J. G. Bartlett, and N. R. Black low, (Eds.) Infectious Diseases. (pp. 14931502). Philadelphia, PA: WB Saunders Company.

Huss, H. H. (1997): Control of indigenous pathogenic bacteria in seafood. Food Control 8(2): 91-98.

International Organization for standardization / technical specification (ISO/ TS218721) (2007): Specifies a horizontal method for the detection of the two main pathogenic Vibrio spp. causing intestinal illness: V.parahaemolyticus and V.cholerae.

International Organization for standardization/technical specification (ISO/TS21872-2) (2007): Specifies a horizontal method for the detection of the enteropathogenic Vibrio spp. causing illness in or via the intestinal tract, other than $V$. parahaemolyticus and $V$. cholerae. Include $V$. fluvialis, $V$. mimicus and $V$. vulnificus.

Jaksic, S.; Uhitil, S.; Patrak, T.; Bazulic, D. and Karolyi, L.G. (2002): Occurrence of Vibrio spp. in sea fish, shrimps and bivalve molluscs from the Adriatic Sia. Food Control; 13:491-493.

Jhonstone, W.A.; Nicholason, F.J.; Roger, A. and Stroud, G.D. (1994): Freezing and refrigerate storage in fisheries. Technical paper No.334Rome. FAO143pp.

Mozaffarian, D. and Rimm, E. B. (2006): Fish intake, contaminants, and human health. JAMA 296:1885-1899.

Noorlis, A.; Ghazali, F. M.; Cheah, Y. K.; Tuan Zainazor, T. C.; Ponniah, J.; Tunung, R.; Tang, J. Y. H.; Nishibuchi, M.; Nakaguchi, Y. and Son, R. (2011): Prevalence and quantification of Vibrio species and Vibrio parahaemolyticus in freshwater fish at hypermarket level. International Food Research Journal,18:689-695.

Ozer, S.;Aslan, G.; Tezcan, S.; Bulduklu, P. S.;Serin, M. S. and Emekdas, G. (2008): Genetic heterogeneity and antibiotic susceptibility of Vibrio alginolyticus strains isolated from Horse-Mackerel (Trachurus trachurus L., 1758). Turkish Journal of Veterinary and Animal Sciences, 32(2), 107-112.

Pruzzo, C.; Huq, A.; Colwell, R. R. and Donelli, G. (2005): Pathogenic Vibrio species in the marine and estuarine environment.In S. Belkin, and R. R. Colwell (Eds.).Oceans and health: Pathogens in the marine environment (pp. 217-251). New York, NY: Springer.

Raissy, M.; Rahimi, E.; Azargun, R.; Moumeni, M.; Rashedi, M. and Sohrabi, H. R. (2013): Molecular detection of Vibrio spp. in fish and shrimp from the persian gulf. Journal of Food Biosciences and Technology, Islamic Azad University, Science and Research Branch, 5(2):49-52.

Rao, B. and Surendran, P. (2013): Pathogenic Vibrios in Penaeus Mond on Shrimp Hatcheries and Aquaculture Farms. Fishery Technol. 50: 161-167.

Rosche, T. M.; Smith, B. and Oliver, J. D. (2006): Evidence for an intermediate 
colony morphology of Vibrio vulnificus. Applied and Environmental Microbiology, 72, 4356-4359.

Sanjeev, S. (2002): Pathogenic halophilic Vibrios in seafoods. In: Quality Assurance in Seafood Processing, 252pp. T.S. Gopala Krishna Iyer, M.K. Kandoran, Mary Thomas and P.T Mathew (Eds). Central Institute of Fisheries Technology and Society of Fisheries Technologists (India), Cochin.

Shimohata, T. and Takahashi, A. (2010): Diarrhea induced by infection of Vibrio parahaemolyticus. J. Med. Invest., 57:179-182.
Sujeewa, A. K. W., Norrakiah, A. S., and Laina, M. (2009): Prevalence of toxic genes of Vibrio parahaemolyticus in shrimps (Penaeus monodon) and culture environment. International Food Research Journal, 16, 8995.

Tarr, C.; Patel, J.; Puhr, N.; Sowers, E.; Bopp, C. and Strockbine, N. (2007): Identification of Vibrio isolates by a multiplex PCR assay and rpoB sequence determination. J. Clin. Microb., 45(1): 134-140.

Utsalo, S.J. (2008): Men and the invisible world of microbes; the transactions and the legacies thereof. University of calabar 41st inaugural lecture. 19-20. 